\title{
Increased Oxidative Damage Associated with Unfavorable Cytogenetic Subgroups in Chronic Lymphocytic Leukemia
}

\author{
Rosa Collado, ${ }^{1}$ David Ivars, ${ }^{2}$ Isabel Oliver, ${ }^{2}$ Carmen Tormos, ${ }^{3}$ Mercedes Egea, \\ Amparo Miguel, ${ }^{1}$ Guillermo T. Sáez, ${ }^{3,4,5}$ and Félix Carbonell ${ }^{1,2}$ \\ ${ }^{1}$ Service of Hematology, CDB-University General Hospital of Valencia, Avenida Tres Cruces 2, 46014 Valencia, Spain \\ ${ }^{2}$ Department of Medicine, Faculty of Medicine, University of Valencia, Avenida Blasco Ibáñez 13, 46010 Valencia, Spain \\ ${ }^{3}$ CIBERobn, Biomedical Network Research Centre in Physiopathology of Obesity and Nutrition, Choupana s/n, \\ 15706 Santiago de Compostela, Spain \\ ${ }^{4}$ Department of Biochemistry and Molecular Biology, Faculty of Medicine, University of Valencia, Avenida Blasco Ibáñez 13, \\ 46010 Valencia, Spain \\ ${ }^{5}$ Service of Clinical Analyses, CDB-University General Hospital of Valencia, Avenida Tres Cruces 2, 46014 Valencia, Spain \\ Correspondence should be addressed to Rosa Collado; collado_ros@gva.es
}

Received 16 February 2014; Revised 30 May 2014; Accepted 11 June 2014; Published 26 June 2014

Academic Editor: Natarajan Muthusamy

Copyright (C) 2014 Rosa Collado et al. This is an open access article distributed under the Creative Commons Attribution License, which permits unrestricted use, distribution, and reproduction in any medium, provided the original work is properly cited.

\begin{abstract}
Oxidative stress contributes to genomic instability in chronic lymphocytic leukemia (CLL), but its relationship with the acquisition of specific chromosomal abnormalities is unknown. We recruited 55 untreated CLL patients and assessed 8-oxo-2' -deoxyguanosine (8-oxo-dG), glutathione, and malondialdehyde (MDA) levels, and we compared them among the cytogenetic subgroups established using fluorescence in situ hybridization (FISH). Significant increases in 8-oxo-dG and/or MDA were observed in patients with unfavorable cytogenetic aberrations (17p and 11q deletions) compared to the 13q deletion group. TP53 deletion patients exhibited a diminished DNA repair efficiency. Finally, cases with normal FISH also showed enhanced 8-oxo-dG, which could result in adverse outcomes.
\end{abstract}

\section{Introduction}

Chronic lymphocytic leukemia (CLL) is the most common leukemia in Western countries and characterized by a variable clinical course, in which a portion of patients survive for long time periods without treatment, while others can experience early progression and subsequent death.

Based on fluorescence in situ hybridization (FISH) results, cytogenetic aberrations have been detected in $80 \%$ of patients with CLL. Patients with del(17p13) and del(11q2223), which affect the TP53 and ATM genes, respectively, have an unfavorable outcome followed by patients with trisomy 12. In contrast, patients with del(13q14), as the sole abnormality, exhibit prolonged survival times [1]. Recently, whole genome sequencing and improved culture techniques have provided additional information on novel recurrent alterations in CLL, such as mutations in NOTCH1, SF3B1,
MYD88, XPO1, and BIRC3 genes, IGH translocations, and loss/gain of chromosome $8 \mathrm{p} / 8 \mathrm{q}$ [2-4]. Interestingly, clonal evolution at the molecular level has been described in CLL. Tumor B-cells harbor different combinations of driver and passenger mutations that expand and evolve over time as response to changes in their local environment. This genetic diversity of cancer cells is essential for progression of the disease $[5,6]$.

On the other hand, accumulation of reactive oxygen species (ROS) results in a state of redox imbalance known as oxidative stress, which contributes to genomic instability. Previous analyses have demonstrated an impairment in the antioxidant defense system and an enhancement in the damaged DNA base 8-oxo-2' -deoxyguanosine (8-oxo-dG) in both the preleukemic state of monoclonal B-cell lymphocytosis and CLL $[7,8]$. However, little is known regarding the relationship between the presence of oxidative damage 
TABLE 1: Summary of clinical and cytogenetic characteristics of the CLL cases included in the present study.

\begin{tabular}{lc}
\hline Patient characteristics $(n=55)$ & $71(47-92)$ \\
\hline Age (years) & $30(54.5 \%)$ \\
Male & \\
Binet stage & $49(89.1 \%)$ \\
A & $5(9.1 \%)$ \\
B & $1(1.8 \%)$ \\
C & $28.6(7.30-240.0)$ \\
White blood cell count $\left(\times 10^{9} / \mathrm{L}\right)$ & $23.2(5.6-233)$ \\
Lymphocyte count $\left(\times 10^{9} / \mathrm{L}\right)$ & $13.8(9.1-16.8)$ \\
Hemoglobin $(\mathrm{g} / \mathrm{L})$ & $189.0(20.0-373.0)$ \\
Platelet count $(9109 / \mathrm{L})$ & $358.0(115-1086.0)$ \\
Lactate dehydrogenase $(\mathrm{U} / \mathrm{L})$ & $2.3(1.0-6.54)$ \\
$\beta 2-$ Microglobulin $(\mathrm{mg} / \mathrm{L})$ & $22(59.4 \%)$ \\
ZAP70 positive* $(n=37)$ & $12(26.6 \%)$ \\
CD38 positive $(n=45)$ & \\
FISH abnormalities & $18(32.7 \%)$ \\
del(13q14) & $8(14.5 \%)$ \\
Trisomy 12 & $6(11.0 \%)$ \\
del $(11 q 22)$ & $6(11.0 \%)$ \\
del $(17$ p13) & $17(31.0 \%)$ \\
Normal FISH &
\end{tabular}

Values are given as median (range) or number (\%).

${ }^{*}$ Positivity was considered when ZAP70 > 20\% and CD38 > 30\%.

and the acquisition of specific chromosomal aberrations. The aim of the present study was to assess different oxidative stress biomarkers in the context of the recurrent cytogenetic subgroups established using FISH in CLL.

\section{Materials and Methods}

2.1. Patients. The study included 55 untreated patients who were diagnosed with CLL according to IWCLL criteria [9]. This cohort was previously reported in Collado et al. [7] referring only to their oxidative stress status without relating to cytogenetic abnormalities pattern. All patients provided their written informed consent, and the study was performed according to the Helsinki declaration. The median age was 71 years (range: $47-92$ years), and $89 \%$ of the subjects belonged to Binet stage A. The most important clinical and cytogenetic features of the studied patients are summarized in Table 1.

2.2. Blood and Urine Sampling. Heparinized whole blood was diluted with RPMI 1640 medium (Gibco BRL), and mononuclear cells were isolated by Lymphoprep (Nycomed) centrifugation. Cells were stored at $-80^{\circ} \mathrm{C}$ until analysis. Twenty-four-hour urine samples were collected and homogenized. Then, urine samples were frozen at $-20^{\circ} \mathrm{C}$ until use.

2.3. DNA Isolation and Enzymatic Digestion. Cellular DNA was isolated following the method in which chloroform isoamyl alcohol $(24: 1)$ was used instead of phenol to remove proteins. Isolated DNA was washed twice with $70 \%$ ethanol, dried, and dissolved in $200 \mu \mathrm{L}$ of $10 \mathrm{mM}$ Tris- $\mathrm{HCl}, 0.1 \mathrm{mM}$ EDTA, and $100 \mathrm{mM} \mathrm{NaCl}$ ( $\mathrm{pH}$ 7.0) for enzymatic digestion. To this end $5 \mu \mathrm{g}$ of DNA/ $\mu \mathrm{L}$ (total DNA content $200 \mu \mathrm{g}$ ) was incubated with 100 units of DNase I in $40 \mu \mathrm{L}$ of Tris/ $\mathrm{HCl}$ $\left(10 \mathrm{mM}\right.$ ) and $10 \mu \mathrm{L}$ of $0.5 \mathrm{M} \mathrm{MgCl}_{2}$ (final concentration: $20 \mathrm{mM}$ ) at $37^{\circ} \mathrm{C}$ for $1 \mathrm{~h}$. The $\mathrm{pH}$ of the reaction mixture was then lowered with $15 \mu \mathrm{L}$ of $0.5 \mathrm{M}$ sodium acetate ( $\mathrm{pH}$ 5.1); $10 \mu \mathrm{L}$ of nuclease $\mathrm{P} 1$ ( 5 units) and $30 \mu \mathrm{L}$ of $10 \mathrm{mM} \mathrm{ZnSO}_{4}$ were added to give a final concentration of $1 \mathrm{mM}$, and the mixture was incubated for $1 \mathrm{~h}$. After adjusting the $\mathrm{pH}$ with $100 \mu \mathrm{L}$ of $0.4 \mathrm{M}$ Tris/HCl (pH 7.8), followed by addition of $20 \mu \mathrm{L}$ of alkaline phosphate ( 3 units), the samples were incubated for $30 \mathrm{~min}$. Enzymes were precipitated with acetone (5 volumes) and removed by centrifugation, and the supernatant was evaporated to dryness.

2.4. Lymphocyte and Urinary 8-oxo-dG Assay. The DNA hydrolysates were dissolved in HPLC grade water and filtered through a $0.2 \mathrm{~mm}$ syringe filter before the samples were applied onto a Waters ODS HPLC column $(2.5 \times 0.46$ i.d.; $5 \mu \mathrm{m}$ particle size). The amounts of 8 -oxo-dG and $\mathrm{dG}$ in the DNA digest were measured by electrochemical and UV absorbance detection, respectively, under the appropriated elution conditions. Standard samples of dG and 8-oxo-dG were analyzed to assure their good separation and to allow the identification of those moieties derived from cell DNA. To carry out the detection of urinary 8-oxo-dG, we followed the method described by Collado et al. [7]. The 8-oxo-dG values were expressed as ratios to urine creatinine concentrations given in $\mathrm{mmol} / \mathrm{mL}$.

2.5. Glutathione and Lipid Peroxidation Assay. Glutathione (GSH) content of cells was measured according to the method of Brigelius et al. [10]. Malondialdehyde (MDA) levels were analyzed by HPLC. Briefly, the technique employs the hydrolysis of plasma lipoperoxides by boiling in dilute phosphoric acid. MDA is one of the hydrolysis products and reacts with thiobarbituric acid (TBA) to form MDA(TBA)2 adduct, and plasma proteins are precipitated with methanol and removed from the reaction mixture by centrifugation. The resulting extract is fractionated by HPLC on a column of silica gel, to separate the MDA-TBA adduct, which finally is eluted with methanol/phosphate buffer and quantified spectrophotometrically at $532 \mathrm{~nm}$.

2.6. Fluorescence In Situ Hybridization. Interphase FISH analyses were performed on fixed cells obtained from $72 \mathrm{~h}$ peripheral blood cultures stimulated with phorbol 12myristate 13-acetate (TPA). The following probes were used: LSI ATM/CEP11, CEP12, LSI D13S319/LSI13q34, and LSI TP53/CEP17 (Abbot Co., Des Plaines, IL). Hybridization signals were evaluated under a fluorescence microscope (Eclipse E800, Nikon) equipped with a charge-coupled device (CCD) camera run by Cytovision software (Applied Imaging, Newcastle upon Tyne, UK). The number of interphase nuclei analyzed was 200 per sample. The cut-off values were $5 \%$ for CEP12 probe and 10\% for LSI ATM/CEP11, D13S319/13q34, and TP53/CEP17 probes. 
TABLE 2: Oxidative stress parameters and cytogenetic subgroups in CLL patients.

\begin{tabular}{|c|c|c|c|c|c|c|}
\hline & $\begin{array}{c}\operatorname{del}(13 \mathrm{q} 14) \\
n=18 \\
\text { Mean } \pm \mathrm{SD}\end{array}$ & $\begin{array}{c}\text { Trisomy } 12 \\
n=8 \\
\text { Mean } \pm \text { SD }\end{array}$ & $\begin{array}{c}\text { del(11q22) } \\
n=6 \\
\text { Mean } \pm \text { SD }\end{array}$ & $\begin{array}{c}\text { del }(17 \mathrm{p} 13) \\
n=6 \\
\text { Mean } \pm \text { SD }\end{array}$ & $\begin{array}{c}\text { Normal FISH } \\
n=17 \\
\text { Mean } \pm \text { SD }\end{array}$ & $P$ value $^{\mathrm{a}}$ \\
\hline Lymphocytes 8-oxo-dG/10 $\mathrm{dG}$ & $39.40 \pm 15.69$ & $44.65 \pm 12.26$ & $43.58 \pm 16.82$ & $54.46 \pm 21.66$ & $57.17 \pm 18.45$ & 0.034 \\
\hline $\begin{array}{l}\text { Urinary 8-oxo-dG } \\
\text { (nmol/mmol creatinine) }\end{array}$ & $19.70 \pm 15.32$ & $22.87 \pm 15.13$ & $27.31 \pm 15.03$ & $12.22 \pm 4.50$ & $18.76 \pm 11.60$ & 0.676 \\
\hline Glutathione (nmol/mg prot.) & $28.28 \pm 5.08$ & $26.15 \pm 5.75$ & $35.48 \pm 9.00$ & $26.72 \pm 6.35$ & $28.30 \pm 8.09$ & 0.118 \\
\hline MDA (nmol/mg prot.) & $1.14 \pm 0.61$ & $1.04 \pm 0.74$ & $2.09 \pm 1.73$ & $2.08 \pm 0.78$ & $1.48 \pm 0.78$ & 0.050 \\
\hline
\end{tabular}

8-oxo-dG: 8-oxo-2-deoxyguanosine; MDA: malondialdehyde; SD: standard deviation.

${ }^{a}$ To determine whether there were any global significant differences between the means of cytogenetic subgroups, we performed the one-way analysis of variance (ANOVA) test.

2.7. Statistical Analysis. The normal distribution was tested using the Shapiro-Wilk test. One-way analysis of variance (ANOVA) and Student's $t$-test were used to analyze differences among groups. Results are expressed as mean \pm standard deviation (SD). The statistical package SPSS, version 15.0 (SPSS Inc., Chicago, IL, USA), was used for all analyses. A two-sided $P$ value $\leq 0.05$ was considered significant.

\section{Results and Discussion}

CLL demonstrates a highly variable disease course, which is partly explained by the process of clonal evolution. Moreover, antioxidant and oxidative stress variations greatly influence genetic and epigenetic cascades underlying altered gene expression in human carcinogenesis [11]. However, the effect of oxidative stress levels on cytogenetic heterogeneity in CLL is unknown. This study included a cohort of 55 untreated patients. Interphase FISH analysis revealed eighteen patients with 13q14 deletion as the sole abnormality, eight patients with trisomy 12, six patients who presented deletion of ATM gene at 11q22-23, and six patients who harbored 17p13 deletion affecting the TP53 gene. In seventeen cases, no abnormality was detected using the 4-probe panel. We measured the most representative oxidative stress parameters, such as 8-oxo-dG, and glutathione and malondialdehyde (MDA) levels in Bcells and urine from CLL patients and compared these values among the cytogenetic subgroups (Table 2).

Increasing knowledge regarding the use of new biomarkers in the early detection and followup of cancer has attracted attention within the last years. Repair of modified guanine prior to DNA replication is an essential feature for the maintenance of cell homeostasis because 8 -oxo-dG is a mutagenic base that can result in $\mathrm{GC} \rightarrow \mathrm{TA}$ transversions. The frequency of mutations generated by 8 -oxo-dG presence in mammalian cell DNA is $2.5-4.8 \%$; therefore, increased levels of 8-oxo-dG may contribute to gene instability, affecting the normal function of oncogenes and tumor suppressor genes [12]. In lymphocytes from CLL patients, we detected global significant differences $(P=0.034)$ compared to the 8 oxo-dG levels among the five cytogenetic groups assessed. Interestingly, patients with a deletion in TP53 and the normal FISH group showed higher concentrations of the damaged base $(54.46 \pm 21.66$ and $57.17 \pm 18.458$-oxo-dG/10 6 dG, resp.). As shown in Figure 1(a), significant increases in 8-oxo-dG level were observed in the normal FISH group compared with the favorable prognostic $13 \mathrm{q}$ deletion group $(57.17 \pm$ 18.45 versus $39.40 \pm 15.698$-oxo-dG/10 $\left.{ }^{6} \mathrm{dG}, P=0.004\right)$. Similarly, we detected a trend towards significance $(P=$ 0.071) when comparing patients with TP53 and 13q deletions, which might be due to the small number of cases in the TP53 deletion group. It has been widely established that activated p53 is involved in growth arrest, DNA repair, apoptosis, and senescence pathways. However, Sablina and colleagues [13] have recently postulated a new role for p53, suggesting that p53 may extend its protective function by participating in antioxidant defense. Genes such as SOD2, GPX1, ALDH4A, HI95, and PA26 encode products that act as antioxidants and are modulated by $\mathrm{p} 53$. Moreover, downregulation of $\mathrm{p} 53$ elevates intracellular ROS, thereby increasing the mutation rate and karyotype instability. In these sense, Macedo et al. [14] also described increased oxidative damage in carriers of the germline TP53 p.R337H mutation in families with LiFraumeni syndromes. Our data were consistent with these findings, where defective p53 derived from TP53 deletion in CLL cells resulted in an increased level of 8-oxo-dG. The occurrence of important oxidized DNA base concentrations among patients with deletions and/or mutations of TP53 in CLL may explain the poor prognosis observed in these cases, in addition to the involvement of TP53 alterations in complex karyotypes $[15,16]$. Furthermore, the observed DNA damage in the normal FISH group could contribute to the emergence of karyotypic aberrations with adverse prognostic features that have been previously described by Rigolin et al. [17] in one-third of CLL patients with normal FISH. In fact, two of our cases carried karyotypic abnormalities in regions not covered by the 4 -probe FISH panel used. One case harbored a deletion $\operatorname{del}(12)(\mathrm{p} 12)$, and the other one showed a translocation $\mathrm{t}(2 ; 7)(\mathrm{p} 21 ; \mathrm{q} 32)$.

On the other hand, 8 -oxo-dG is present in the urine as a consequence of the base/nucleotide excision repair pathways [12]. Although no significant differences were found among urinary 8-oxo-dG levels in the present study, it is noteworthy that patients with TP53 deletion exhibited lower concentrations $(12.22 \pm 4.50 \mathrm{nmol} / \mathrm{mmol}$ creatinine $)$, suggesting a diminished DNA repair efficiency in this group. The mechanism underlying this decrease is still not known but 


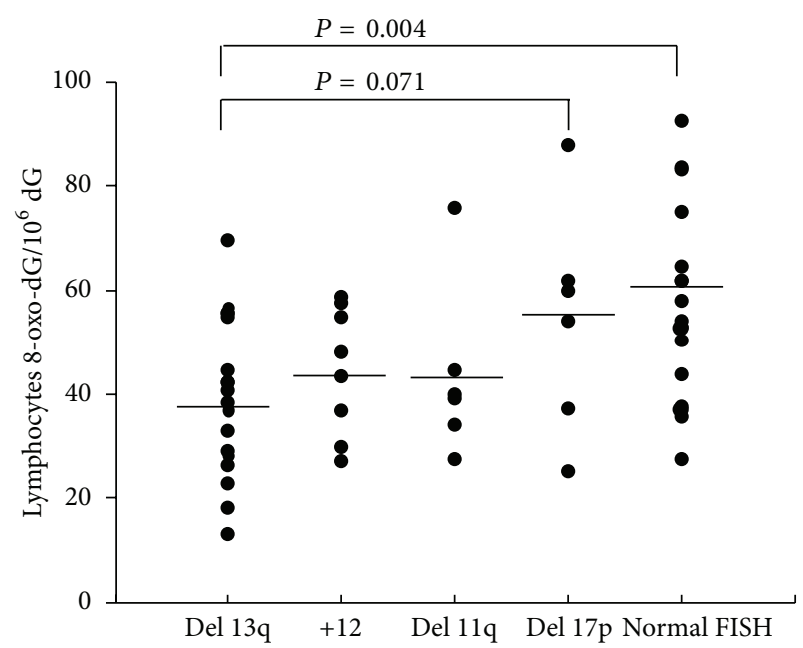

(a)

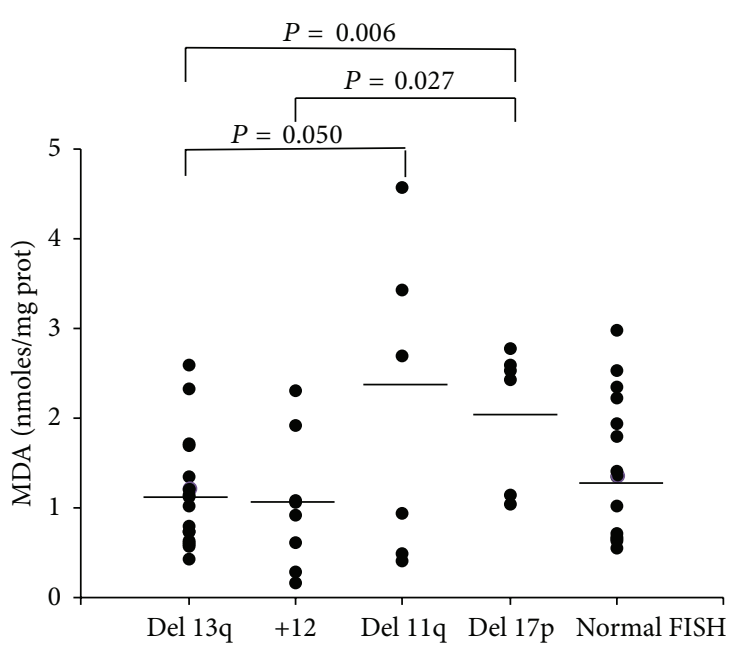

(b)

FIGURE 1: Analysis between cytogenetic subgroups with respect to (a) lymphocytes 8-oxo-dG/10 ${ }^{6}$ dG levels and (b) malondialdehyde-MDA levels. The mean value is shown for each group (bars). $P$ values were determined on the basis of the Student's $t$-test.

is most likely due to an alteration in $O G G 1$ gene expression [12]. An additional important element in the antioxidant defense is ROS detoxification via the activation of glutathione peroxidase and elevation of thiols. Glutathione is an antioxidant intracellular thiol that is increased in circulating blood cells of CLL patients [7, 8]. However, we have not observed any differences among the analyzed cytogenetic subgroups. Likely, increases in the GSH levels were not sufficient to prevent oxidative stress in CLL cells.

Finally, lipid peroxidation may cause significant changes in the functional properties of biomembranes, resulting in altered cell signaling and in the release of toxic cellular products. In this study, we used MDA as a marker of lipid peroxidation. Differences in MDA levels among cytogenetic groups reached global statistical significance $(P=0.05)$. Thus, we observed an association between plasma MDA content and poor prognosis genetic subgroups. CLL patients with TP53 and ATM deletions demonstrated significantly higher MDA levels than patients with 13q deletions and trisomy 12 (Figure 1(b)). These results confirmed the findings observed by Macedo et al. [14] in TP53 p.R337H carriers. In addition, Shiloh and Ziv [18] have recently proposed a role of ATM in regulating the cellular redox balance, indicating its effects on mitochondrial physiology. ATM-deficient cells have been associated with mitochondrial dysfunction. Consistent with this finding, lipid peroxidation observed in CLL patients with ATM deletions may disturb the mitochondrial membrane potential, thereby affecting its normal activity.

\section{Conclusions}

Taken together, our results showed that B-cells from CLL patients with unfavorable cytogenetic aberrations were susceptible to injury caused by ROS, resulting in increased levels of oxidized DNA bases as 8-oxo-dG and/or lipid peroxidation. Because a portion of patients with CLL acquire new aberrations during the course of the disease, we presumed that a deficiency in the TP53 tumor suppressor gene could promote oxidation-mediated mutagenesis, thereby contributing to accelerated malignant progression. Moreover, attention must be focused on mutations resulting in altered activity of DNA repair mechanisms as well as polymorphisms of DNA repair genes that contribute to resistance to treatment with alkylating agents, such as chlorambucil, or with the purine analog fludarabine. Moreover, further studies are required to elucidate the genetic content of CLL patients with normal FISH. The occurrence of the new unfavorable NOTCH1, SF3B1, and BIRC3 mutations in this patient group is an important issue that we have to analyze in the future.

Lastly, the present study supports the possibility of using antioxidants in combination with existing therapeutic strategies to improve survival in CLL patients. In this line, Jitschin et al. [19] have recently treated CLL cells with the antioxidant $\mathrm{N}$-acetyl-cysteine (NAC). Oxidative stress attenuates immune responses by leading to dysfunctions and even apoptosis of NK- and T-cells, suggesting a role in tumor immune escape. The addition of NAC prevented CLL cell-mediated T-cell dysfunction. The authors concluded that treatment of CLL cells using antioxidants could neutralize endogenous ROS and protect the immune system. Such strategies have been successfully implemented in other hematological entities such as acute myeloid leukemia [20].

\section{Conflict of Interests}

The authors declare that there is no conflict of interests.

\section{Authors' Contribution}

Rosa Collado and David Ivars contributed equally to this study. 


\section{Acknowledgments}

This study was supported in part by the University of Valencia, Spain. G. T. Sáez obtained grants from the Instituto de Salud Carlos III (FIS PI10/0082, RD06/0045, and CB12/03/30016) and Generalitat Valenciana (ACOMP 2012238).

\section{References}

[1] H. Döhner, S. Stilgenbauer, A. Benner et al., "Genomic aberrations and survival in chronic lymphocytic leukemia," The New England Journal of Medicine, vol. 343, no. 26, pp. 1910-1916, 2000.

[2] C. Haferlach, F. Dicker, T. Weiss et al., "Toward a comprehensive prognostic scoring system in chronic lymphocytic leukemia based on a combination of genetic parameters," Genes Chromosomes and Cancer, vol. 49, no. 9, pp. 851-859, 2010.

[3] X. S. Puente, M. Pinyol, V. Quesada et al., "Whole-genome sequencing identifies recurrent mutations in chronic lymphocytic leukaemia," Nature, vol. 475, no. 7354, pp. 101-105, 2011.

[4] D. Rossi, S. Rasi, V. Spina et al., "Integrated mutational and cytogenetic analysis identifies new prognostic subgroups in chronic lymphocytic leukemia," Blood, vol. 121, no. 8, pp. 14031412, 2013.

[5] D. A. Landau, S. L. Carter, P. Stojanov et al., "Evolution and impact of subclonal mutations in chronic lymphocytic leukemia," Cell, vol. 152, no. 4, pp. 714-726, 2013.

[6] A. Schuh, J. Becq, S. Humphray et al., "Monitoring chronic lymphocytic leukemia progression by whole genome sequencing reveals heterogeneous clonal evolution patterns," Blood, vol. 120, no. 20, pp. 4191-4196, 2012.

[7] R. Collado, I. Oliver, C. Tormos et al., "Early ROS-mediated DNA damage and oxidative stress biomarkers in Monoclonal B Lymphocytosis," Cancer Letters, vol. 317, no. 2, pp. 144-149, 2012.

[8] A. M. Oltra, F. Carbonell, C. Tormos, A. Iradi, and G. T. Sáez, "Antioxidant enzyme activities and the production of MDA and 8-oxo-dG in chronic lymphocytic leukemia," Free Radical Biology \& Medicine, vol. 30, no. 11, pp. 1286-1292, 2001.

[9] M. Hallek, B. D. Cheson, D. Catovsky et al., "Guidelines for the diagnosis and treatment of chronic lymphocytic leukemia: A report from the International Workshop on Chronic Lymphocytic Leukemia updating the National Cancer InstituteWorking Group 1996 guidelines," Blood, vol. 111, no. 12, pp. 5446-5456, 2008.

[10] R. Brigelius, C. Muckel, T. P. M. Akerboom, and H. Sies, "Identification and quantitation of glutathione in hepatic protein mixed disulfides and its relationship to glutathione disulfide," Biochemical Pharmacology, vol. 32, no. 17, pp. 2529-2534, 1983.

[11] D. Ziech, R. Franco, A. Pappa, and M. I. Panayiotidis, "Reactive oxygen species (ROS) - induced genetic and epigenetic alterations in human carcinogenesis," Mutation ResearchFundamental and Molecular Mechanisms of Mutagenesis, vol. 711, no. 1-2, pp. 167-173, 2011.

[12] B. Tudek, A. Winczura, J. Janik, A. Siomek, M. Foksinski, and R. Oliński, "Involvement of oxidatively damaged DNA and repair in cancer development and aging," American Journal of Translational Research, vol. 2, no. 3, pp. 254-284, 2010.

[13] A. A. Sablina, A. V. Budanov, G. V. Ilyinskaya, L. S. Agapova, J. E. Kravchenko, and P. M. Chumakov, "The antioxidant function of the p53 tumor suppressor," Nature Medicine, vol. 11, no. 12, pp. 1306-1313, 2005.
[14] G. S. Macedo, L. Lisbôa da Motta, J. Giacomazzi et al., "Increased oxidative damage in carriers of the germline TP53 p.R337H mutation," PLoS ONE, vol. 7, no. 10, Article ID e47010, 2012.

[15] R. Collado, J. Hueso, A. I. Cabello et al., "New translocations in a case of atypical B-cell chronic lymphocytic leukemia: involvement of ATM, MLL, and TP53 genes," Cancer Genetics and Cytogenetics, vol. 169, no. 2, pp. 176-178, 2006.

[16] J. Delgado, B. Espinet, A. C. Oliveira et al., "Chronic lymphocytic leukaemia with $17 \mathrm{p}$ deletion: a retrospective analysis of prognostic factors and therapy results," The British Journal of Haematology, vol. 157, no. 1, pp. 67-74, 2012.

[17] G. M. Rigolin, F. Cibien, S. Martinelli et al., "Chromosome aberrations detected by conventional karyotyping using novel mitogens in chronic lymphocytic leukemia with "normal" FISH: correlations with clinicobiologic parameters," Blood, vol. 119, no. 10, pp. 2310-2313, 2012.

[18] Y. Shiloh and Y. Ziv, "The ATM protein kinase: regulating the cellular response to genotoxic stress, and more," Nature Reviews, vol. 14, no. 4, pp. 197-210, 2013.

[19] R. Jitschin, A. D. Hofmann, H. Bruns et al., "Mitochondrial metabolism contributes to oxidative stress and reveals therapeutic targets in chronic lymphocytic leukemia," Blood, vol. 123, no. 17, pp. 2663-2672, 2014.

[20] M. Brune, S. Castaigne, J. Catalano et al., "Improved leukemiafree survival after postconsolidation immunotherapy with histamine dihydrochloride and interleukin-2 in acute myeloid leukemia: results of a randomized phase 3 trial," Blood, vol. 108, no. 1, pp. 88-96, 2006. 


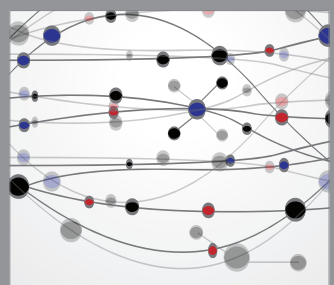

The Scientific World Journal
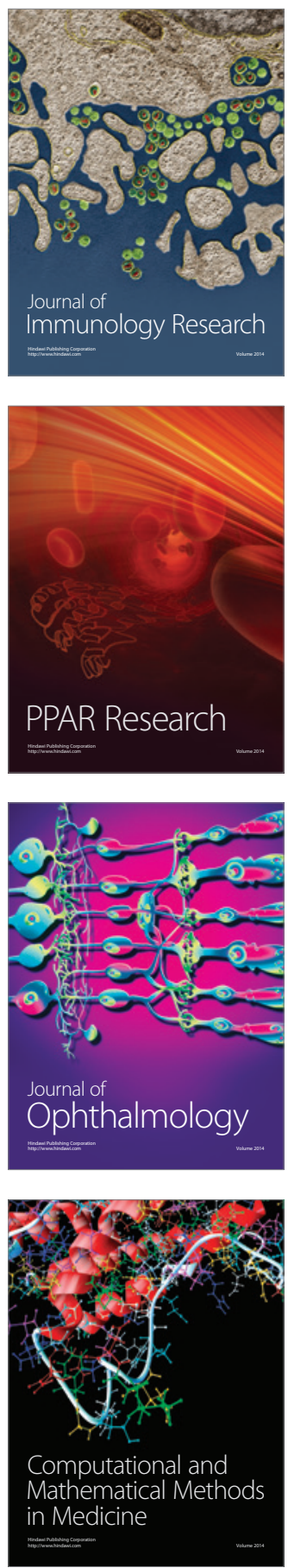

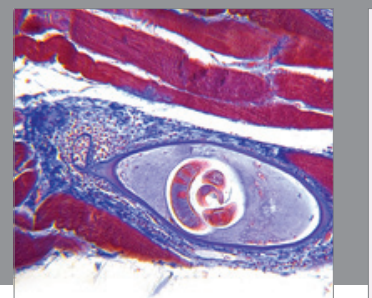

Gastroenterology

Research and Practice
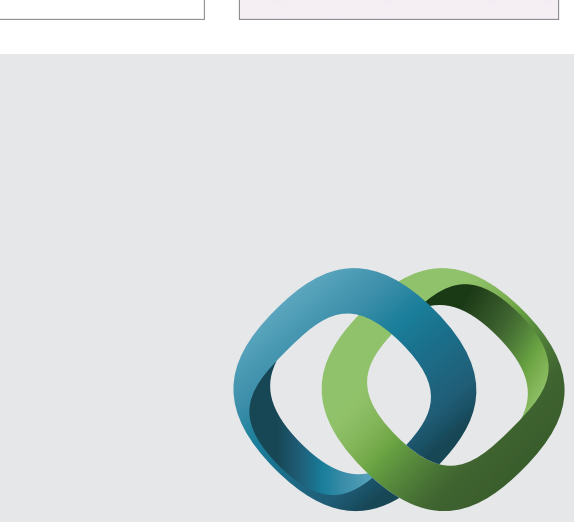

\section{Hindawi}

Submit your manuscripts at

http://www.hindawi.com
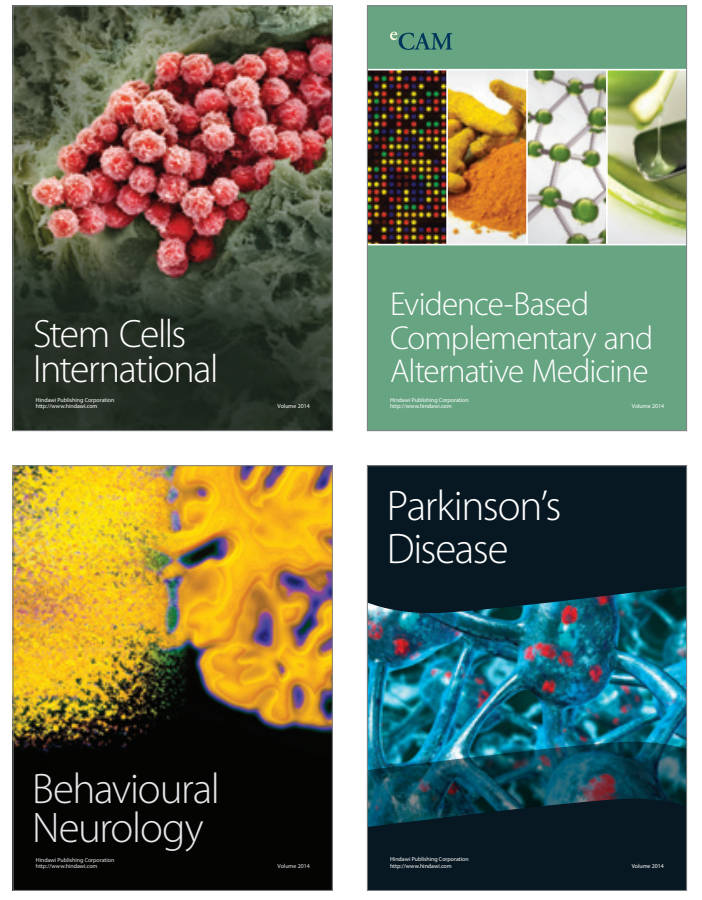
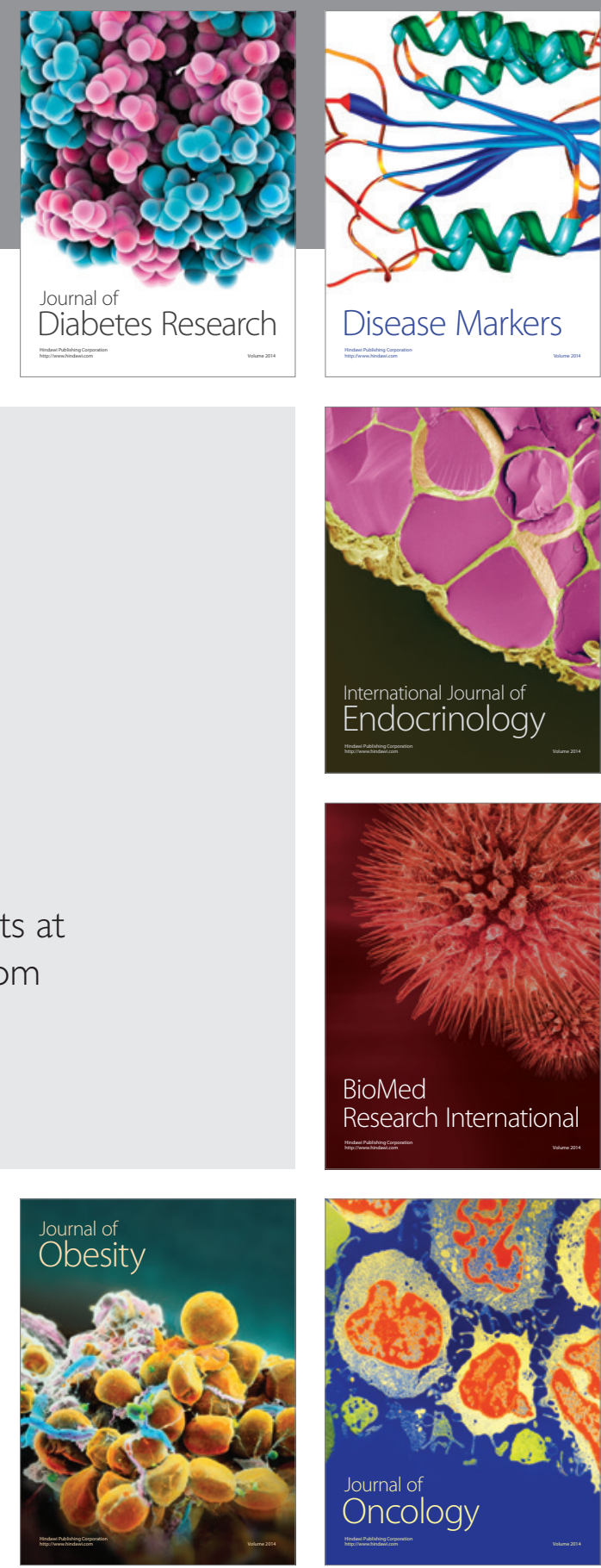

Disease Markers
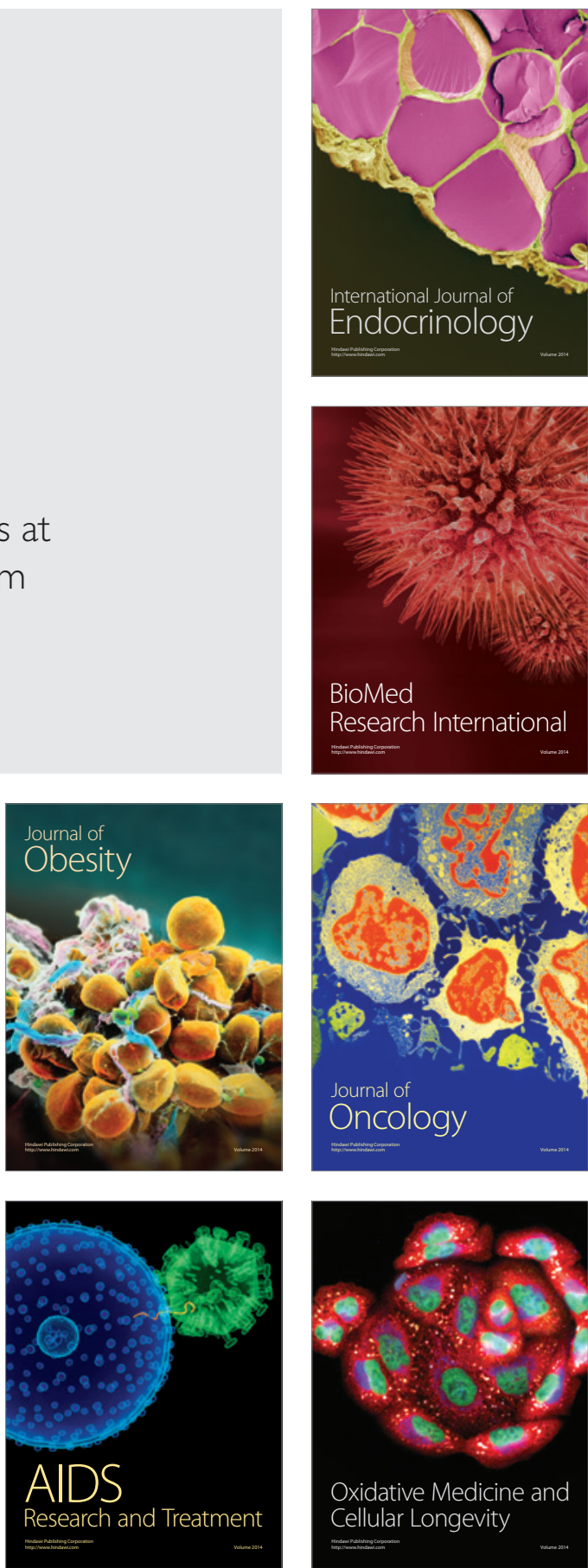